\title{
Reversible pulmonary trunk banding III: Assessment of myocardial adaptive mechanisms-contribution of cell proliferation
}

Maria C. D. Abduch, DVM, PhD, ${ }^{a}$ Renato S. Assad, MD, PhD, ${ }^{\mathrm{b}}$ Miguel O. Rodriguez, MD, PhD, ${ }^{\mathrm{b}}$ Acrisio S. Valente, MD, ${ }^{\mathrm{b}}$ José L. Andrade, MD, PhD, ${ }^{c}$ Léa M. M. Demarchi, MD, PhD, ${ }^{a}$ Miguel B. Marcial, MD, PhD, ${ }^{b}$

and Vera D. Aiello, MD, $\mathrm{PhD}^{\mathrm{a}}$

From the Laboratory of Pathology, ${ }^{a}$ Division of Pediatric Surgery, ${ }^{\mathrm{b}}$ and Echocardiography Laboratory, ${ }^{\mathrm{c}}$ Heart Institute (InCor) University of Sao Paulo Medical School, Sao Paulo, Brazil.

Supported by Fundação de Amparo à Pesquisa do Estado de São Paulo (FAPESP), grants 2002/11721-6 and 2004/08825-0.

Received for publication Aug 23, 2006; revisions received Nov 20, 2006; accepted for publication Dec 13, 2006.

Address for reprints: Dr Vera Demarchi Aiello, Heart Institute (inCor), University of Sao Paulo School of Medicine, Laboratory of Pathology, Av. Dr. Eneas C Aguiar, 44, Sao Paulo, SP 05403-000, Brazil (E-mail: anpvera@incor.usp.br).

J Thorac Cardiovasc Surg 2007;133:1510-6 $0022-5223 / \$ 32.00$

Copyright (๑) 2007 by The American Association for Thoracic Surgery

doi:10.1016/j.jtcvs.2006.12.010
Objectives: Rapid ventricular conditioning induced by pulmonary artery banding has been recommended for patients with transposition of the great arteries who have lost the chance for the arterial switch operation or whose systemic (right) ventricle failed after the atrial switch. The present study was designed to experimentally evaluate 2 types of pulmonary artery banding (continuous and intermittent) and verify histologically the changes (hypertrophy or hyperplasia or both) of cardiomyocytes and vascular and interstitial cells from the stimulated ventricle beyond the neonatal period.

Methods: Twenty-one goats, 30 to 60 days old, were divided into 3 groups, each comprising 7 animals, as follows: control group (no surgical procedure); continuously stimulated group (systolic overload maintained for 96 hours); and intermittently stimulated group (4 periods of 12-hour systolic overload, alternated with a resting period of 12 hours). The animals were then killed for histologic and immunohistochemical analysis of the hearts. Murine monoclonal antibody Ki-67 was used as a proliferation cell marker. Myocardial collagen area fraction was determined by Sirius red staining.

Results: For both stimulated groups, a significant increase occurred in right ventricular cardiomyocytes and respective nuclei diameters compared with the controls $(P<.05)$. The number of Ki-67-positive cardiomyocytes and interstitial/vessel cells from the right ventricle was augmented in both trained groups in relation to the left ventricle $(P<.05)$. There was no significant difference in the right ventricular collagen area fraction from both trained groups compared with controls.

Conclusions: Irrespective of the shorter training time (periods of overload intercalated with resting), the intermittent stimulation regimen was able to produce a similar training of the subpulmonary ventricle compared with the continuous stimulation regarding mass acquisition, cell hypertrophy, and hyperplasia.

$\mathrm{L}$

eft ventricular retraining induced by pulmonary artery banding (PAB) has been indicated for patients with transposition of the great arteries (TGA) beyond the neonatal period and patients who present with right (systemic) ventricular failure in congenitally corrected TGA or after failed atrial baffle operations. ${ }^{1,2}$ Previous experimental studies have demonstrated that an increase in afterload leads to sustained ventricular hypertrophy in only a few days. ${ }^{3}$

In the clinical setting of TGA, a few centers have documented the clinical results of rapid preparation of the left ventricle (LV) in the two-stage Jatene operation. These trials succeeded in their objective, once there was significant cardiac mass acquisition in about 7 days, reducing the risks of complications resulting from the first stage of the anatomical correction in a patient with unprepared LV. However, 


$$
\begin{aligned}
& \text { Abbreviations and Acronyms } \\
& \begin{aligned}
\text { ANOVA } & =\text { analysis of variance } \\
\text { LV } & =\text { left ventricle } \\
\text { PAB } & =\text { pulmonary artery banding } \\
\text { PT } & =\text { pulmonary trunk } \\
\text { RV } & =\text { right ventricle } \\
\text { TGA } & =\text { transposition of the great arteries } \\
\text { VS } & =\text { ventricular septum }
\end{aligned}
\end{aligned}
$$

some patients may have unsatisfactory contractile performance in the late follow-up. ${ }^{2,4}$ Previous studies from our laboratory have demonstrated experimentally expressive muscular mass acquisition induced by an adjustable PAB system. ${ }^{5,6}$

At present, there is great concern about the quality of ventricular hypertrophy, leading to questions regarding the most efficient and physiologic training program and the adaptive mechanisms involved in the process. $1,2,7,8$ On the other hand, the hypertrophy of an athlete's heart, characterized by normal or increased capillary density with little or no fibrosis, is a consequence of physiologic stresses like endurance exercise, intermittent by nature. Based on the fact that both the cardiac and the skeletal muscles are striated, it has been proposed that a fitness program similar to that developed by athletes would lead to an acquired muscular mass with better performance. ${ }^{9,10}$ Besides that, the knowledge that the myocardium is a postmitotic organ, which means that cardiomyocytes are capable of proliferating after the neonatal period, leads to the hypothesis that myocyte hyperplasia may be an important feature in mass acquisition, although it has not been clarified to what extent it occurs. ${ }^{11,12}$

The present study was designed to experimentally evaluate 2 types of PAB (continuous and intermittent) and to analyze histologically the structural phenotype changes (hypertrophy and/or hyperplasia) of the contractile (cardiomyocytes) and noncontractile cells (vascular and interstitial) from the stimulated ventricle, beyond the neonatal period.

\section{Materials and Methods}

Twenty-one goats, 30 to 60 days old (beyond the neonatal period), were divided into 3 groups, each with 7 animals: control group, with no surgical procedure; continuously stimulated group; and intermittently stimulated group. All animals received humane care according to the "Guide for Care and Use of Laboratory Animals." 13

\section{Pulmonary Artery Banding Device}

The device used in this study (Braile Biomedica, São José do Rio Preto, SP, Brazil) has been described previously. ${ }^{5}$ It permits a fine control of the pulmonary blood flow percutaneously by adjusting accurately the cross-sectional diameter of the pulmonary trunk
(PT). The prototype is made completely of silicone and consists of 3 parts: a banding ring, extension tube, and an inflation reservoir. The banding ring is a $\mathrm{C}$-shaped hydraulic cuff that compresses the lumen of the PT when expanded, according to the volume injected percutaneously into the inflation reservoir, implanted subcutaneously.

\section{Pulmonary Artery Banding Device Protocol}

The anesthetic and surgical protocols were performed according to previously described techniques. ${ }^{5}$ Catheters were introduced into the descending aorta, right ventricular outflow tract, and PT (distally to the banding) for hemodynamic measurements. Baseline pressures in the right ventricle (RV), PT, and aorta were then taken in the awake animals with the device completely empty. After that, progressive inflation of the device was achieved by percutaneous injection of saline solution in the reservoir to reach a $0.7 \mathrm{RV}$-to-LV systolic pressure ratio, ${ }^{1,2,5}$ as long as it did not cause a drop of more than $10 \%$ in systemic pressure. In cases where clinical signs of severe hypoxia (agitation, dyspnea, or arrythmias) developed after inflation of the banding device, it was deflated to a tolerable value. The animals in the continuously stimulated group remained in RV systolic overload for 96 hours, with progressive inflations every 24 hours, at the maximum limit tolerated, while the intermittently stimulated group was submitted to 4 periods of 12-hour systolic overload, alternated with a resting period of 12 hours. Inflation of the device and pressure measurements were taken daily in both stimulated groups.

\section{Echocardiographic Study}

The echocardiographic evaluation was performed daily, using a 7.5-MHz transducer (Apogee CX, ATL-Advanced Technologies Laboratories, Bothell, Wash). The RV free wall mass was calculated through a bidimensional approach, according to the method described by Pontes and colleagues. ${ }^{14} \mathrm{RV}$ and LV ejection fractions were estimated by area $\times$ length and Teichholz methods, respectively. ${ }^{15}$

\section{Morphologic Study of the Hearts}

After the 96-hour protocol, the animals in the continuously stimulated and intermittently stimulated groups were killed. ${ }^{5,13}$ All the hearts, including those from animals in the control group, were fixed in $10 \%$ buffered formalin for 24 hours. Transversal sections of both ventricles and the ventricular septum were obtained. After routine histologic processing, 5- $\mu \mathrm{m}$ sections were stained with hematoxylin-eosin and Sirius red. Sections also underwent immunohistochemical reactions with Ki-67.

\section{Myocardial Fiber and Nucleus Diameter}

The morphometric measurements were carried out with an interactive computer-assisted image analyzer (Leica Quantimet; Leica Cambridge Ltd, Cambridge, UK) in 60 longitudinally and/or transversely sectioned cardiomyocytes, as already described. ${ }^{3}$

\section{Collagen Area Fraction}

Histologic samples stained with Sirius red were studied for collagen area fraction by means of the computed image analysis system color detection (Quantimet-Leica). Data were collected from 20 


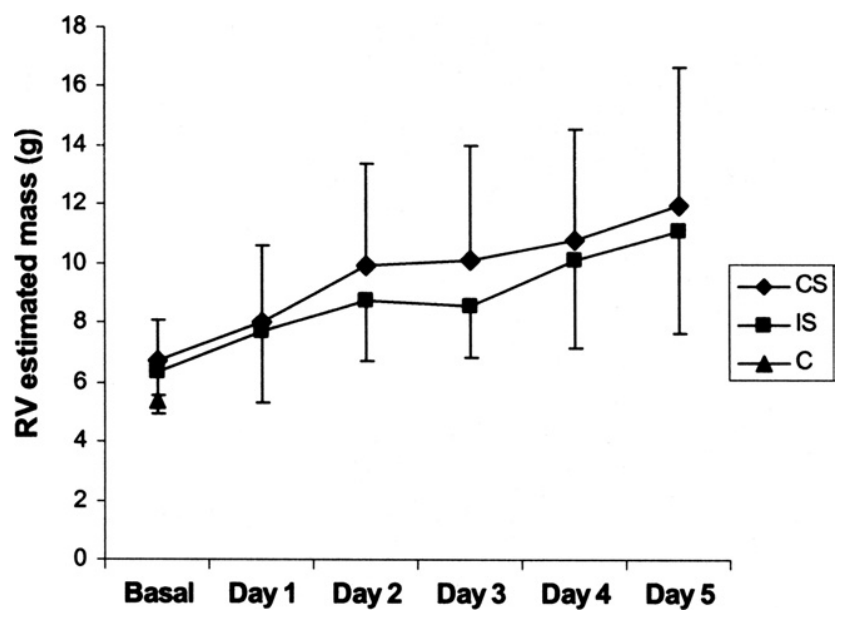

Figure 1. RV estimated mass (g) during training days. $R V$, Right ventricle; $C$, control group; $C S$, continuous stimulated group; $I S$, intermittent stimulated group.

fields at a magnification of $200 \times$. Regions occupied by vessels greater than $50 \mu \mathrm{m}$ or histologic artifacts were avoided.

\section{Immunohistochemical Study}

Five micrometer-thick sections underwent immunohistochemical reactions using the streptavidin-peroxidase immunohistochemical method. Murine monoclonal antibody Ki-67, clone MIB-1, code number IM0505 (DAKO, Grostrup, Denmark) was used as proliferation cell marker. According to previous studies, this marker has been used in goats. ${ }^{16} \mathrm{Ki}-67$-positive cardiomyocytes and interstitial/vessel cells were microscopically quantified in the RV, $\mathrm{LV}$, and ventricular septum (VS). The index of cell proliferation was calculated as follows: for each section of the heart (RV, LV, and VS), 4000 cells were counted (2000 cardiomyocytes and 2000 interstitial/vessel cells); the number of positive Ki-67 cells/2000 expressed as a percentage represented the index for each cell type. For the sections of the ventricular septum, the index was determined summing up the first 1000 cells counted in each half. Ultimately, for each group, the proportion between contractile and noncontractile elements labeled by the cell proliferation marker was determined.

\section{Statistical Analysis}

Values are expressed as means \pm SE. Analysis of variance (ANOVA) was used to compare the 3 groups; for comparisons between the segments inside each group, the repeated measures ANOVA was used. When data did not show normal distribution, nonparametric tests were used.

\section{Results}

\section{Hemodynamic Study}

The intermittently stimulated group began the experiment with a $9.57 \mathrm{~mm} \mathrm{Hg}$ basal RV-PT mean peak gradient ( $\mathrm{SE}=$ $3.58 \mathrm{~mm} \mathrm{Hg}$ ). The last period inflation (72 hours) caused an $80.00 \mathrm{~mm} \mathrm{Hg}$ gradient ( $\mathrm{SE}=4.92 \mathrm{~mm} \mathrm{Hg}$ ), which represents an increase equal to $736 \%(P=.018$, Wilcoxon nonparametric test). In the continuously stimulated group, the basal mean peak gradient was $15.67 \mathrm{~mm} \mathrm{Hg}(\mathrm{SE}=4.50$ $\mathrm{mm} \mathrm{Hg})$. After 72 hours, this value was $57.14 \mathrm{~mm} \mathrm{Hg}$ ( $\mathrm{SE}=$ $5.22 \mathrm{~mm} \mathrm{Hg}$ ), which means a $265 \%$ rise in RV-PT pressure gradient ( $P=.028$, Wilcoxon nonparametric test). Comparison between the 2 groups regarding the tolerated mean peak gradient indexed to the body weight revealed a significant difference, with greater values for the intermittently stimulated group after 72 hours of training $(P=.008)$.

\section{Right Ventricular Mass Estimated by Echocardiography}

See Figures 1 and 2. Basal RV estimated mass was equal in the 3 groups (ANOVA, $P=.110$ ); however, in both trained groups, the right ventricular mass increased progressively throughout the protocol (ANOVA, $P<.05$ ). Right and left ventricular ejection fractions did not show significant changes in both stimulated groups during the study (mean values $\pm \mathrm{SE}$ for the RV: controls, $0.71 \pm 0.02$; continuous stimulation, $0.67 \pm 0.03$; intermittent stimulation, $0.74 \pm$ 0.03 ; mean values $\pm \mathrm{SE}$ for the $\mathrm{LV}$ : controls, $0.70 \pm 0.02$; continuous stimulation, $0.75 \pm 0.01$; intermittent stimulation, $0.77 \pm 0.01)$.

\section{Collagen Area Fraction of the Right and \\ Left Ventricles}

Microscopically, no evidence of interstitial edema, relevant inflammatory infiltrate, or necrosis in the myocardium was
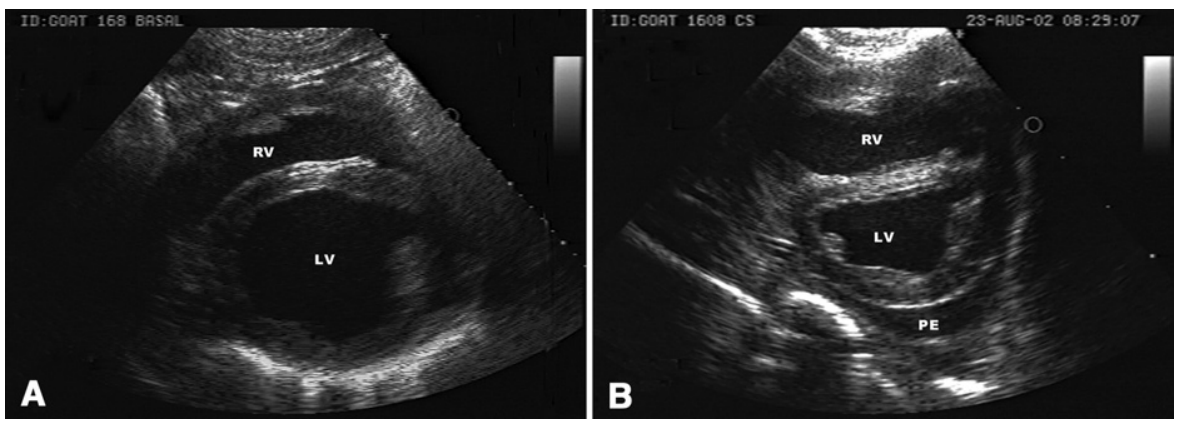

Figure 2. Bidimensional echocardiogram at baseline $(A)$ and after 5 days of training (B) in a CS group goat. $R V$, right ventricle; $L V$, left ventricle; $P E$, pericardial effusion.

1512 The Journal of Thoracic and Cardiovascular Surgery • June 2007 


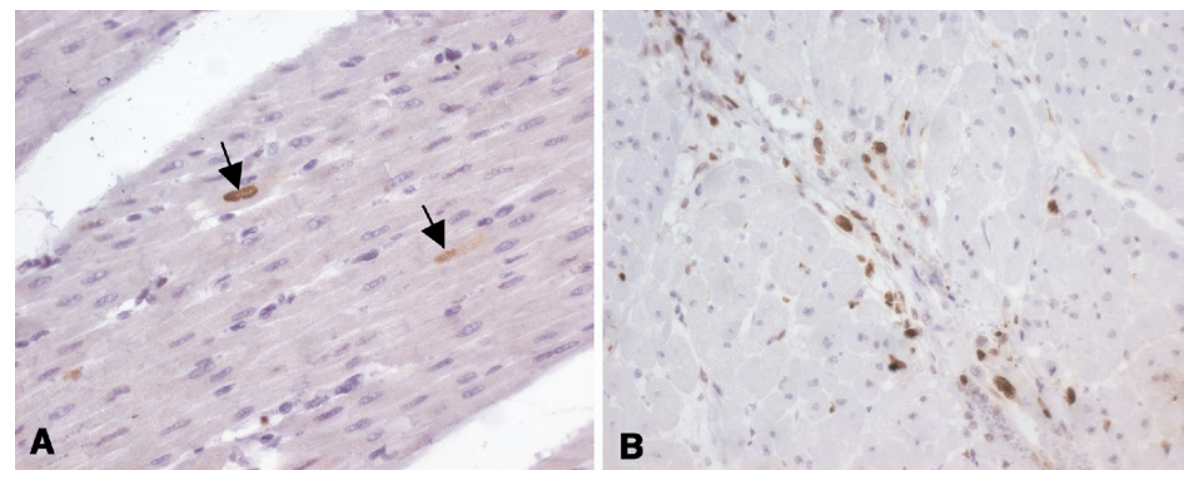

Figure 3. Photomicrographs of the RV myocardium showing Ki-67 immunostaining. A, Arrows indicate 2 labeled cardiomyocyte nuclei. B, Numerous positive nuclei from interstitial and vessel cells. Objective: $40 \times$; counterstaining with Harry's hematoxylin. RV, Right ventricle.

present in the 3 groups analyzed. The mean collagen area fraction was significantly higher in the RV of the 3 groups when compared with the respective LVs (ANOVA, $P=$ .015). There was no statistical difference in the RV collagen content between the groups (ANOVA, $P=.403$ ).

\section{Cell Diameters}

With regard to RVs, stimulated groups had significantly higher values of cell diameter than those of the control group, for both cardiomyocytes and their respective nuclei (ANOVA, $P<.005$ ). Compared with controls, myocyte diameters were $42.17 \%$ and $45.19 \%$ higher in the continuously stimulated and intermittently stimulated groups, respectively. Similarly, considering the cardiac segments inside the groups, RV cardiomyocytes and respective nuclei from the 2 stimulated groups had higher diameters than those of LV and ventricular septum (repeated measures ANOVA, $P<$ $.05)$.

\section{Ki-67-positive Cardiomyocytes and Interstitial/Vessel Cells}

The histologic aspect of Ki-67-labeled cardiomyocytes is demonstrated in Figure 3, A. Higher indexes of proliferating cells were found in the RV of both stimulated groups (continuously stimulated group, $1.13 \%$; intermittently stimulated group, $0.68 \%$ ) when compared with the corresponding LV (continuously stimulated group, $0.37 \%$; intermittently stimulated group, 0.21\%; repeated measures ANOVA, $P=.009$ ) and ventricular septum (continuously stimulated group, $0.21 \%$; intermittently stimulated group, $0.08 \% ; P<.001$; Figure $4, A)$. The histologic aspect of the interstitial and vessel cells labeled with Ki-67 is demonstrated in Figure 3, $B$. In this analysis, the values obtained for the 2 halves of the ventricular septum were significantly different and were treated independently $(P=.024)$. The right septal half had higher values compared with the left one. Analyzing the cardiac segments in the stimulated groups (Figure 4, B), RV had significantly higher indexes of cell proliferation than the LV (continuously stimulated group, $16.32 \%$ vs $2.57 \%$; intermittently stimulated group, $12.36 \%$ vs $1.45 \%$; repeated measures ANOVA, $P<.001)$. The right septal half had statistically higher index values than did LV (continuously stimulated group, 3.73\%; intermittently stimulated group, 4.94\%; $P=.024$ ) and the left septal half (continuously stimulated group, $2.06 \%$; intermittently stimulated group, $1.61 \% ; P=.012$ ). On the other hand, LV did not differ from the left septal half $(P=.527)$. No difference was detected in the cardiac segments of the control group (repeated measures ANOVA, $P=.198$ ).

\section{Proportion Between Numbers of Ki-67-labeled RV} Cells (Cardiomyocytes/Interstitial and Vessel Cells) Statistical analysis of these data did not depict any difference between the 3 groups (Kruskal-Wallis, $P=.4320$ ).

\section{Discussion}

Induced myocardial hypertrophy has been proposed in children with TGA, aiming at preparing the future systemic ventricle to support the new hemodynamic conditions after the anatomical correction (Jatene's procedure). ${ }^{2,17}$ The adaptation of the pulmonary ventricle to the systemic pressures must be effective, which means that the chamber has to keep the mass acquisition and not experience dilation or dysfunction over time. Based on the fitness program of athletes, where the skeletal and cardiac muscles are capable of sustaining a high workload through fiber hypertrophy, a hypothesis arose that perhaps intermittent conditioning of the subpulmonary ventricle could provide better adaptation. ${ }^{9,10}$ However, no consensus exists about what would be the ideal time to impose systolic workload on a ventricle, inducing it to acquire good-quality muscular mass.

Pressure overload induces an increase in cardiac wall thickness without chamber dilation (concentric hypertrophy) for the purpose of normalizing systolic wall stress. ${ }^{18} \mathrm{It}$ is fundamental to determine the primary mechanism of mass acquisition (ie, cell hypertrophy, hyperplasia, or both). Hypertrophy is efficient as an adaptive mechanism in the compensated phase but may evolve into muscle dysfunction and congestive heart failure with time. ${ }^{19}$ Nowadays, it is fully accepted that cardiomyocytes are capable of prolifer- 

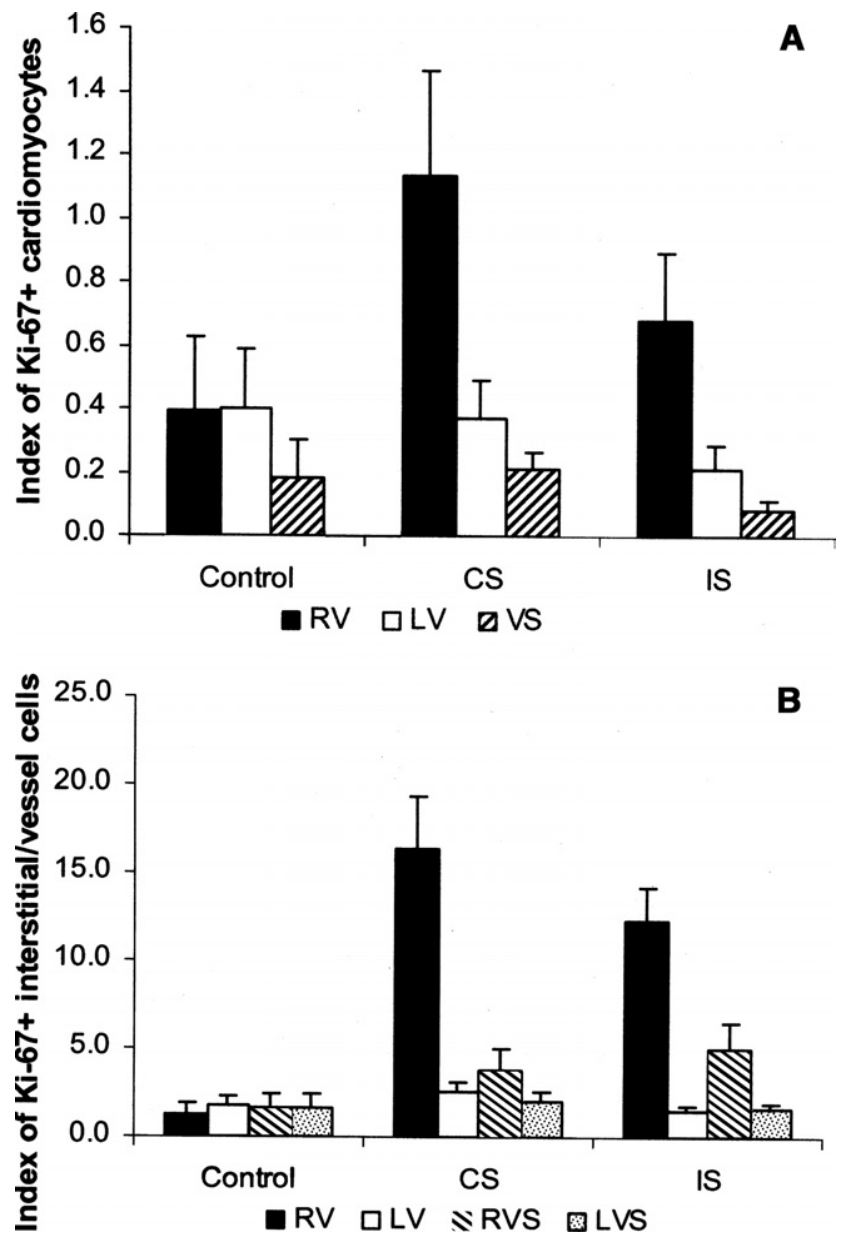

Figure 4. Mean and SE values of: (A) cardiomyocytes Ki-67positive index (number of positive cells/2000 cardiomyocytes expressed as a percentage); (B) interstitial/vessel cells Ki-67positive index (number of positive cells/2000 expressed as a percentage). $R V$, right ventricle; $L V$, left ventricle; $R V S$, right half of ventricular septum; $L V S$, left half of ventricular septum.

ating after the neonatal period. During fetal life, cardiac growth is mainly due to cell division (mitosis). In the neonatal period, a transition occurs from hyperplastic to hypertrophic growth. In the adult heart, most cardiomyocytes do not proliferate, and hypertrophy functions as the fundamental adaptive response. ${ }^{20}$ Therefore, the magnitude of cardiomyocyte hypertrophy or hyperplasia is dependent on the age at which the stimulus is produced. ${ }^{4,8,12}$

\section{Myocardial Hypertrophy}

In the present study, the echocardiogram showed a similar right ventricular mass acquisition for both stimulated groups. The RV free wall thickness, an important parameter in ventricular mass calculation, became similar to the septal and left ventricular wall thicknesses around the third day of device inflation in both groups, despite the fact that 1 of them was stimulated intermittently. Morphometric analysis revealed that for both stimulated groups, hypertrophy of cardiomyocytes occurred, confirming that this mechanism participates in the process of muscle mass acquisition during ventricular training, as has already been demonstrated in other pressure-overload experimental models. ${ }^{18}$

In myocardial hypertrophy caused by other factors, it is well recognized that interstitial cell proliferation is also a feature. The interstitium has important functions, such as support for cardiomyocytes, blood and lymphatic vessels; acting as a defense mechanism against microorganisms; facilitating myocardial nutrient exchanges; and aiding in cell contraction. However, when interstitium enlargement is excessive, it may cause early diastolic dysfunction and, in the final stages, also jeopardizes systolic function. ${ }^{21}$ In this study, no significant difference existed in RV collagen area fraction between the 3 groups. We cannot rule out the possibility that the observation time was not sufficient to demonstrate an increase in the interstitial component. Le Bret and colleagues, ${ }^{10}$ comparing 3 types of pulmonary ventricular training in lambs for 5 weeks, demonstrated no interstitial fibrosis in animals undergoing the intermittent regimen of training in opposition to the other groups, suggesting that the cascade of events initiated with myocardial hypertrophy is not accompanied by fibrosis when it develops in good oxygen conditions (corresponding to the period that the ventricle does not experience an afterload increase). Buccino et al, ${ }^{22}$ studying 26 cats with right ventricular hypertrophy produced by continuous PT constriction for a period of 3 to 90 days, encountered higher collagen concentrations in RVs compared with that in the controls and LVs. The majority of RVs failed after 20 to 50 days. Therefore, it seems that the duration of the training period is important as an inductor of myocardial fibrosis responsible for late heart failure.

\section{Cell Proliferation}

The present study showed that both cardiomyocytes and interstitial/vessel cells are able to improve their capacity for proliferation, under continuous or intermittent elevation in afterload, even beyond the neonatal period. It is important to note that the intermittent regimen of $\mathrm{PAB}$, which potentially could be better tolerated clinically, is as effective as the continuous regimen in inducing RV cardiomyocyte hyperplasia. Although the idea of having a high proliferation index for contractile myocardial cells would be tempting in this model, it must not be forgotten that an increase in their number will also augment the demand for oxygen and nutrients and, consequently, for blood vessels, to maintain the needs of proliferating cells. ${ }^{9,18}$ So, it would be desirable to have a balance between myocardial cells and capillary vessel proliferation, promoting a ventricular conditioning 
that is considered ideal to sustain the requirements of systemic circulation. ${ }^{23}$ Anversa and associates ${ }^{9}$ submitted 5-week-old Wistar-Kyoto rats to intermittent physical training by having them run on a treadmill $1 \mathrm{~h} / \mathrm{d}, 5 \mathrm{~d} / \mathrm{wk}$, for 7 weeks. At the end of the experiment, they found a $16 \%$ increase in myocardial capillary vessels $/ \mathrm{mm}^{2}$, indicating that vascular cell proliferation did occur in this physiologic model of fitness.

It is not easy to distinguish between interstitial cells (mainly fibroblasts) and capillary endothelial cells under optical microscopy, because the small vessels are not always open. Therefore, in the present study, it is not possible to confirm whether the Ki-67-labeled interstitial/vessel cells are predominantly endothelial cells or fibroblasts. Doublelabeling immunohistochemical reactions may elucidate this question in the future.

Regarding the proportion of Ki-67-positive cardiomyocytes and interstitial/vessel cells, no statistical difference existed between the groups (Kruskall-Wallis, $P=.432$ ). Hence, apparently, both fitness regimens are capable of inducing a proportionally equal increase in contractile and noncontractile elements after a period of 96 hours of training.

Myocyte proliferation has been demonstrated under normal and pathologic conditions, such as heart failure or acute myocardial infarction. ${ }^{24,25}$ In the adult heart, a subpopulation of cardiomyocytes exists that is not differentiated, capable of reentering the cell cycle and proliferating. There is no definitive evidence about the exact origin of these undifferentiated cells. They may come from itinerant cells or even from myocardial stem cells. These hypotheses need further investigation. ${ }^{24}$ Several researchers have also verified that the capacity of hyperplasia is accompanied by apoptosis. ${ }^{24-28}$ Both clinical ${ }^{24}$ and experimental ${ }^{28}$ investigations showed that diseased hearts present, simultaneously, signs of cardiomyocyte hyperplasia and programmed cell death. The studies suggest that tissue homeostasis depends on proper relationships between proliferation, differentiation, and apoptosis, so that under severe stress, apoptosis overtakes cell division. ${ }^{28}$ Concomitant cell proliferation and apoptosis would have important implications when a ventricle is prepared to support systemic pressures, once it is desirable that contractile cells proliferate and remain preserved. From a therapeutic standpoint, an index lower than $0.05 \%$ to $0.1 \%$ of proliferating cardiomyocytes would be sufficient to significantly increase the number of contractile cells in a few months, because this growth takes place in a sustained manner, which means without being overcome by apoptosis. ${ }^{20}$ In the present study, training groups had indexes of $1.13 \%$ (continuously stimulated group) and $0.68 \%$ (intermittently stimulated group). However, we did not search for apoptosis in this model.
Another substantial factor to be analyzed in the future would be the quantification of capillaries in the 3 groups studied. The type of training that demonstrates the best balance between contractile cell proliferation and blood vessels, besides the smallest apoptotic index, would be considered as the most adequate to be used in the 2-stage arterial switch operation.

The finding of a higher proliferation index for cells in the right half of the ventricular septum deserves discussion. Feigenbaum $^{29}$ long ago described in echocardiography the presence of a bright line within the ventricular septum, dividing its 2 sides. Boettler and colleagues, ${ }^{30}$ studying hearts from 30 healthy subjects, demonstrated, also through echocardiography, that this line probably represents the VS division in 2 halves (right and left). Results from the present study suggest a different behavior of the 2 septal halves when the RV undergoes pressure overload and corroborate the theories of septal division mentioned above.

\section{Limitations of the Study}

The main limitation of this study is the fact that differences exist between the RVs and LVs with respect to anatomy and physiology. One could argue that experimental results would not be the same if the trained ventricle was the morphologically left one. However, even having knowledge of this limitation, the option to work with healthy animals prevailed because the surgical procedure to change the ventriculoarterial connections would cause high mortality, making the research impracticable. ${ }^{6}$ Moreover, although at first sight RV training could represent a limitation because of the different geometry of the chamber, considering that in our experimental model the coronary arterial circulation is not submitted to a hypertensive regimen due to pressure overload, one can observe that this situation is similar to the one that occurs in the child with transposition requiring ventricular preparation, which would be an advantage. Another restriction to consider is the training time in our 2 groups: animals prepared continuously had PAB for 96 hours, and in the intermittently stimulated group, animals were trained for 48 hours. However, in this study, the intention was to analyze the behavior of the ventricles that underwent rapid preparation, totaling a week of study. The final objective of this line of research is to obtain the best results in the shortest time possible, aiming at optimal clinical application.

\section{Conclusions}

Under the conditions of the present study, the intermittent stimulation regimen, even imposing a shorter training time (periods of overload intercalated to periods of resting), was able to induce a similar response of the myocardium regarding cell hypertrophy and hyperplasia when compared with the continuous stimulation. Moreover, although there was 
an increase in the interstitial cellular activity, it did not impair right ventricular systolic function (represented by the ejection fraction) in both stimulated groups.

\section{References}

1. Iyer KS, Sharma R, Kumar K, Bhan A, Kothari SS, Saxena A, et al. Serial echocardiographic for decision making in rapid two- stage arterial switch operation. Ann Thorac Surg. 1995;60:658-64.

2. Lacour-Gayet F, Piot D, Zoghbi J, Serraf A, Gruber P, Macé L, et al. Surgical management and indication of left ventricular retraining in arterial switch for transposition of the great arteries with intact ventricular septum. Eur J Cardiothorac Surg. 2001;20:824-9.

3. Assad RS, Cardarelli M, Abduch MC, Aiello VD, Maizato M, Barbero-Marcial M, et al. Reversible pulmonary artery banding with a balloon catheter; assessment of rapid pulmonary ventricular hypertrophy. J Thorac Cardiovasc Surg. 2000;120:66-72.

4. Boutin C, Wernovsky G, Sanders SP, Jonas RA, Castaneda AR, Colan SD. Rapid two-stage arterial switch operation. Evaluation of left ventricular systolic mechanics late after an acute pressure overload stimulus in infancy. Circulation. 1994;90:1294-1303.

5. Dias CA, Assad RS, Caneo LF, Abduch MCD, Aiello VD, Dias AR, et al. Reversible pulmonary trunk banding II. An experimental model for rapid pulmonary ventricular hypertrophy. $J$ Thorac Cardiovasc Surg. 2002;124:999-1006.

6. Canêo LF, Dias CA, Assad RS, Abduch MCD, Aiello VD, Moreira LFP, et al. Preparo do ventrículo subpulmonar através de dois diferentes modelos ajustáveis de bandagem do tronco pulmonar: estudo experimental. Rev Bras Cir Cardiovasc. 2001;16:35-48. Abstract in English at: http://www.scielo.br/scielo.php?script $=$ sci_abstract\&pid $=$ S0102-76382001000100006\&lng $=$ en\&nrm $=$ iso\&tlng $=$ en .

7. Taquini AC, Fermoso JD, Aramendia P. Behavior of the right ventricle following acute constriction of the pulmonary artery. Circ Res. 1960; 8:315-8.

8. Dowell RT, McManus RE. Pressure-induced cardiac enlargement in neonatal and adult rats. Circ Res. 1978;42:303-10.

9. Anversa P, Levicky V, Beghi C, McDonald SL, Kikkawa Y. Morphometry of exercise-induced right ventricular hypertrophy in the rat. Circ Res. 1983;52:57-64.

10. Le Bret E, Lupoglazoff JM, Borenstein N, Fromont G, Laborde F, Bachet J, et al. Cardiac "fitness" training: an experimental comparative study of three methods of pulmonary artery banding for ventricular training. Ann Thorac Surg. 2005;79:198-203.

11. Anversa P, Kajstura J. Ventricular myocytes are not terminally differentiated in the adult mammalian heart. Circ Res. 1998;83:1-14.

12. Anversa P, Fitzpatrick D, Argani S, Capasso JM. Myocyte mitotic division in the aging mammalian rat heart. Circ Res. 1991;69:1159-64.

13. Clark JD, Gebhart GF, Gonder JC, Keeling ME, Kohn DF. Special report. The 1996 guide for the care and use of laboratory animals. ILAR J. 1997;38:41-8.
14. Pontes SC Jr, Assef JE, Barretto RB, Chaccur P, Moreira DA, Nina VJS, et al. Estimation of right ventricular mass by two-dimensional echocardiography. J Am Soc Echocardiogr. 2005;18:427-34.

15. Vuille C, Weyman A. Left ventricle I: general considerations, assessment of chamber size and function. In: Weyman AE, editor. Principles and Practice of Echocardiography. 2nd ed. Philadelphia: Lea \& Febiger, 1994; p. 575-624.

16. Flores JM, Sanchez MA, Nieto A, Sanchez B, Gonzalez M, Garcia $P$. Detection of estrogen alpha and progesterone receptors and cell proliferation in the uterus during early pregnancy in the goat. Theriogenology. 2001;56:341-55.

17. Corno AE, Hurni M, Payot M, Sekarski N, Tozzi P, von Segesser LK. Adequate left ventricular preparation allows for arterial switch despite late referral. Cardiol Young. 2003;13:49-52.

18. Anversa P, Ricci R, Olivetti G. Quantitative structural analysis of the myocardium during physiologic growth and induced cardiac hypertrophy: a review. J Am Coll Cardiol. 1986;7:1140-9.

19. Borow KM, Arensman FW, Webb C, Radley-Smith R, Yacoub MH. Assessment of left ventricular contractile state after anatomic correction of transposition of the great arteries. Circulation. 1984;69:106-12.

20. Soonpaa MH, Field LJ. Survey of studies examining mammalian cardiomyocytes DNA synthesis. Circ Res. 1998;83:15-26.

21. Weber KT. Cardiac interstitium in health and disease: the fibrillar collagen network. J Am Coll Cardiol. 1989;13:1637-52.

22. Buccino RA, Harris E, Spann JF Jr, Sonnenblick EH. Response of myocardial connective tissue to development of experimental hypertrophy. Am J Physiol. 1969;216:425-8.

23. Tomanek RJ, Searls JC, Lachenbruch PA. Quantitative changes in the capillary bed during developing, peak, and stabilized cardiac hypertrophy in the spontaneously hypertensive rat. Circ Res. 1982;51:295304.

24. Zorc M, Vraspir-Porenta O, Zorc-Pleskovic R, Radovanovic N, Petrovic D. Apoptosis of myocytes and proliferation markers as prognostic factors in end-stage dilated cardiomyopathy. Cardiovasc Pathol. 2003; 12:36-9.

25. Narula N, Narula J, Zhang PJ, Haider N, Raghunath PN, Brittin R, et al. Is the myofibrillarlytic myocyte a forme fruste apoptotic myocyte? Ann Thorac Surg. 2005;79:1333-7.

26. Dispersyn GD, Ausma J, Thoné F, Flameng W, Vanoverschelde JLJ, Alessie MA, et al. Cardiomyocyte remodelling during myocardial hibernation and atrial fibrillation: prelude to apoptosis. Cardiovasc Res. 1999;43:947-57.

27. James TN. Normal and abnormal consequences of apoptosis in the human heart. Апnи Rev Physiol. 1998;60:309-25.

28. Sarkar S, Chawla-Sarkar M, Young D, Nishiyama K, Rayborn ME, Hollyfield JG, et al. Myocardial cell death and regeneration during progression of cardiac hypertrophy to heart failure. J Biol Chem. 2004;279:52630-42.

29. Feigenbaum H. Diseases of the myocardium. In: Feigenbaum H, editor. Echocardiography. 4th ed. Philadelphia: Lea \& Febiger; 1986. p. 514-47.

30. Boettler P, Claus P, Herbots L, McLaughlin M, D’Hooge J, Bijnens B, et al. New aspects of the ventricular septum and its function: an echocardiographic study. Heart. 2005;91:1343-8. 